\title{
Brand Community Way in Digital Era: Valuable Interaction of Business, Sociability, and Usability in Indonesian Consumers Experience
}

\author{
Zinggara Hidayat \\ Communication Department, BINUS Graduate Program \\ Bina Nusantara University \\ Jakarta, Indonesia \\ z.hidayat@binus.edu
}

\begin{abstract}
This paper focuses on the study of Indonesian brand community and the practice of digital marketing communication on social media. This literature reviews, observation, and qualitative data analysis conducted to adopt the concept of valuing the community life includes the business values, sociability values, and usability values. The sample taken from the most valuable Indonesian brand and its online brand communities for each line of business such as Airline, Banking and Finance, Entertainment, Personal Care, Home Care, Real Estate, Retail, Automotive, Telecom Provider, and Hardware retail. Results showed that business value of brand is reflected on the financial values. However, the significant contribution to the values is achieved through the existence of brand community both online and offline. Sociability values and usability values supported the success of business values. Sociability values more influenced to the communities based on the active participants, reciprocity on the interaction, trustworthiness among the members and others. Usability values also develop community power to achieve inter-member cohesiveness such as productivity, user satisfaction, minimize the error and others. Furthermore, brand communities are the way of consumer society in digital era. It's have broader targets for building people engagement and business sustainability.
\end{abstract}

Keywords: Digital Marketing Communication, Online Brand Community, Social Media, Indonesia

\section{INTRODUCTION}

Indonesia's population of 261 million is the fourth largest after China (1.379 bi), India (1.324 bi), and the United States (323 mi).[1] The amount of human resources is not only make Indonesia a very potential as a market but also as a location of production and distribution of world trade. The growth of ecommerce sector in Indonesia increased rapidly and there was a change in consumer buying behavior that shifted from conventional shopping habit to online shopping. Investment Coordinating Board (BKPM) revealed the value of investment in the e-commerce sector in 2017 reached more than US\$ 4 mi with growth $60 \%-80 \%$ per year.[2] Furthermore, it is estimated that growth will increase because online shopping has become part of the daily life of the current society. This positive development of e-commerce in Indonesia requires adequate knowledge in digital marketing communication, especially for corporations and small businesses.
Digital technology is very important and dominant for the achievement of marketing objectives [3] so the involvement of that new media is now a necessity for every brand and entity. All businesses have changed and therefore have to adjust their business model. The digital technology revolution is changing business and all our lives.[4] Human way of life is changing, including how to communicate, shop, travel, work, communicating the business, and how to interact each other.

The inventor of the 4Ps Marketing concept is E. Jerome McCarthy who classically describes Products, Price, Place and Promotion. Now, the concept of digital marketing communication has changed the concept to $10 \mathrm{Ps}$, which includes 4 Ps plus 6 Ps [5] such as performance, presence, proximity, pertinent, process, personal, preferences, profit, and people. The contemporary concept supported by the technological environment as a new and major way of doing business. The new business model is experiencing growth with the approach of a business towards digital fully approach.[6]

Communication is the sharing of signs and meanings between participants. This process distributes phrases in words or stories, images and videos in online platforms and the contexts. In this sense, social media content involves human storytelling with a foundation within informational and persuasive communication.[7]

The social network is formed and it is supported by technology in each era. Internet technology evolved as a medium that people use to interact with each other. Social media become glue and liaison between members and become the arena of creation and exchange of user-generated content. [8] Now, social media is an integral part of people's lives. Changes in media usage habits cause people engaged. Individuals and communities seeking information, sharing ideas, and the way to communicate are now very different from before. Then social media is becoming the most influential channel of information [9] and entertainment. Social media has become part of the daily life of individuals and communities. That is what changed the marketing communication strategy. Marketers want to maximize opportunities to reach and interact with consumers.[10]

Digital marketing communication puts YouTube as one of the most under-utilized platforms by many digital marketers. 
Other social media is inseparable from YouTube because everyone can produce and share the content. YouTube makes it easy to integrate the interface. Participants can conveniently upload, publish, and view streaming videos without high levels of technical knowledge. [11] So, YouTube has become part of the lives of individuals, community, corporations, and governments and anyone in the digital age as participatory culture.[12] Participants can create content and sharing together as a community and that is what the 'ordinary' and 'total sums of human experience.' YouTube is everything that humans create or do together.

Brand Community is one of the active participants who use YouTube as a forum for interaction between members and anyone. Created content may include commercial or social messages. Commercial content generally comes from corporate sources such as advertising is a form of marketing communication. The goal is to influence the consumer's thoughts, feelings, and actions. Soft-commercial is also often produced by the brand community because its advertising content is always a creative, innovative, aspiring and attractive field.[13]

A brand is created as an identity to be easily recognizable to consumers. Information about brands in the form of stimuli sent by companies and other sources is stored into the audience memory. Information received by individuals is discussed together into groups. Sharing the knowledge and experience of the group will bring closer member relationships or possibly the opposite or making it antibrand.[14]

Online brand communities must be continually evaluated and improved on an on-going basis. It takes precise measurements in the context of business value and social value Therefore community success and its impact on the brand is the goal of community formation. The measurement includes community website activity, community membership and participation, and email campaign rates. Other measurement are traffic from community to ecommerce and corporate pages, community-generated sales leads, press attention, search engine rankings, customer feedback, changes in public awareness and perception of on company, etc.[15]

This paper discusses some of the research questions: 1) How to do the measuring success of online brand community? 2) How brand community digital marketing communication practices on social media as evidence from Indonesia?

\section{LITERATURE REVIEW}

\section{A. Communication Persuasion}

Persuasive appeals are not confined to creating associations suited to the target audience. Persuasive communication is a process to take account of the receiver of the information. Then, the source of the information and the content and presentation of the message.[16] Meanwhile, persuasive commercial messages is designed inter-textual to the extent that the participants or viewers to understand and appreciate it fully. That genre is known informally as "real life, real people" advertising, and it makes use of handheld cameras and naturalistic settings and dialogue.[17] Furthermore, the persuasion categories divided into three principles such as strategy (includes information, influence, emotion, and mere exposure), general tactics (includes resistance, acceptance, message, and attention), and mediaspecific tactics (includes still media and motion media).[18]

\section{B. Social Media and Consumer Loyalty}

Social media has now become an integral part of the daily lives of citizens. Even social media has taken role as source of information and entertainment then its replaces the role of conventional media. Citizens as a community of lovers of a brand gather and discuss anything about their experience of the product. However, the following question is do social media enhance customer loyalty. For example, in the use of social media marketing (SMM) among brands social media can identify attributes among perceived activities, value equity, relationship equity, and purchase intention. There are five constructs of perceived SSM activities such as entertainment, interaction, trendiness, customization, and word of mouth.[19] Until now, citizens rely heavily on information through its gadget to determine every purchase decision of a brand. Peer experiences are also a consideration, but the peer group interacts and exchanges experiences through social media. Social media play a role in building the impression, image, and experience of customers and ultimately achieve customer loyalty.

\section{Community Engagement}

Community is a group of people who share a common interest. Community also is an organization of people or small groups, interesting in interaction and gathering, and have feeling of mutual responsibility. Community engagement and sustainability are the goal of relationships endeavor between companies and society. The perspective of communication theory considers that there are two notions of community concept. First, community is the set of people who inhabit a certain geographic place, they are unit bigger than family and neighborhood but smaller than the state, region, or nation such as the people who live in local area such as cities, towns, and school districts. Second, community is a term of reference for a discrete set of people who share a culturally marked identity. Online community means the people who share an interest or activity such as the Facebook community, YouTube participants, Instagram followers, blogs, and other social media community.[20]

People or consumers have emotional involvement or commitment to do many things towards a brand. The community engages with brand growth. Specifically, more recently the 'consumer brand engagement' (CBE) concept reflect the nature of consumers' particular interactive brand relationships, relative to traditional concepts, including 'involvement.' Participants think creatively, work, and create something to enrich their experience of a brand. Even often members of the community work unconditionally. And then consumer's positively valence are brand-related cognitive, emotional and behavioral activity during or related to focal consumer/brand interactions.[21]

Consumer engagement in a virtual brand community is a new way for citizens to gather. As a previous study, use the Netnographic methodology to explore the nature and scope of consumer engagement in online brand community. The interaction of everyday life online can be understood as an integral part of real life. The consumer engagement reflects their interactive experience and value co-creation among community participants. In the medium to long term, engaged 
consumers exhibit enhanced consumer loyalty, satisfaction, empowerment, connection, emotional bonding, trust and commitment.[22]

Other previous research about the roles of brand community and community engagement founded that the brand communities and social media often overlap. Social media is an ideal environment for building brand communities. However, there is limited research about the benefits and consequences of brand communities established on social media platforms. It is about how consumers' relationship with the elements of a brand community based on social media (i.e. brand, product, company, and other consumers) influence brand trust. Online trust is not only needed for the strengthening of community but also people outside the community. So, community engagement amplifies the strength of the relationships consumers make with the elements of brand community. Of course it has a moderating effect such relationships on brand trust.[23]

\section{Brand Community}

A community is a group of members who share a common interest for a particular brand. They create a parallel world around that brand. There are two forms of relationship to the brand community between the brand and the community, and between community members. Brand community is built by the power of social media. It is based on brand communities that focus for understanding customer engagement actively growing market potential. Brand community based on social media have positive effects on the main community elements and value creation practices in the communities as well as on brand trust and brand loyalty. Brand communities have positive effects on community markers such as shared consciousness, shared rituals and traditions, and obligations to society. In addition, brand communities have positive effects on value creation practices such as social networking, community engagement, impressions management, and brand use. Brand community in any previous study could enhance brand loyalty through brand use and impression management practices.[24]

\section{E. The Values of Social Media}

The most important thing in the emergence of brand community as part of digital marketing communication is the measurement of success from a business perspective. Social media is used extensively by various companies, both multinational, large national, medium, and small businesses. Average companies are used to using YouTube, Blog, Twitter, Facebook and other social media to gain business value. This is the virtual customer environments (VCEs) that created by online communities. To gain business value, business organizations need to incorporate community building as part of digital marketing communication strategy. A previous research for example, described that the Fortune 500's used four of the most popular social media platforms-Twitter, Facebook, blogs, and client-hosted forums - to interact with customers. Community development can gain business value from social media, therefore firms need to develop implementation strategies based on mindful adoption, community building, and absorptive capacity.[25]

\section{F. Online Community}

The successful of online community and its organizational related to marketing communication and customer service can be reviewed by social media performance. As a new communication channel it's important to assess the outcomes, such as the ROI of social media marketing.[26] The others are the size of the community and its growth rate, the proportion of active members, and how much time they spend on the community. Meanwhile, important to consider about the number of likes, comments, and re-tweets of the enterprise micro-blog. Community then linked with the quantity of discussions about the company and its products. Also, the effects on sales of "likes" and other social network stimuli [27] and the relative impact of user-and marketer-generated content.[28] Especially for micro-blogging, the metrics are the number of tweets about brands, re-tweets, followers, replies, and the valence of tweets.

Content analysis used to find the number of productrelated discussions and the number of social-related discussions of customers to measure social media of brand community performance.[29] Furthermore, because social media is also used to support some business activities, such as marketing, branding, sales, customer services and management, and product development, it can create traditional business value. Re-tweeting a company's tweet, can spread the information about the company widely.[30] Other research compared two strategies of two retail-apparel brands showed company with proactive social media strategy would receive more positive postings from customers.[31] Also, customer satisfaction would lead them to more engage, and at the end the result in a higher brand loyalty.[32]

In other case such as entertainment industry, also found that the negative reviews about a movie in Twitter. Directly it is decrease the revenue in the first weekend after the release and harm the early adoption.[33] Members and the public immediately respond to tweets. That is, there is a dynamics of user-generated content and stock performance indicated by volume of customers' reviews in social media.[34] Tweet and re-tweet give a positive effect on business value or vice versa. Meanwhile, many researchers have studied the performance impact of marketing resources, including market performance, and customer service performance.[35]

The activities of brand community members are both online and offline communication such as their offline actions determined by the decision from their online interactions, and vice versa. Other researcher examines the impact of online such as information quality, system quality and service quality, and offline such as offline activities features. This indicated that perceived of usefulness, perceived ease of use and offline activities are determinants of sustainability of brand communities and society. Conversation in the forum or chat will show the awareness of members of the brand, especially concerning quality, price, services, usefulness and so forth [36].

\section{METHODS}

\section{A. Mixed Methods}

Literature review, observation, and other document analysis are done first. Next comes with a qualitative content analysis of the social media content of various brand communities.[37]

Variables used in accordance with their respective concepts, namely "Brand business value", and "Brand 
community performance" which divided in "Sociability value" and "Usability value".

Sampling technique is done with search engine in Google and YouTube with keywords such as "brand community in Indonesia", "Top 10 Indonesian brand community", and "Most Valuable Indonesian brand", "Most popular brands on Facebook from Indonesia", etc. The researcher selected ten brand communities representing ten line of business with the brand judgmentally. Consideration is the brand communities that appear in the top ten brand communities' by the Indonesian most valuable brand based on the category or line of business. Then the sample are Garuda Indonesia (Airline), BCA (Banks), Indovision (Entertainment), Pond's (Personal Care), Rinso (Home Care), Ciputra (Real Estate), Matahari (Retail), Yaris Club (Automotive), and Telkomsel (Telecom Provider), ACE (Hardware retail).

Some types of social media used by the brand community are analysed qualitatively both on verbal and nonverbal texts of communication, i.e. YouTube, Blogs, Facebook, Blogs, Instagram, and Twitter. Each brand community has all these kind of social media. The analysed content includes audiovisual, verbal, texts, and visuals published in each of these social media.

\section{B. Categorization and Coding}

Each brand social media brand is analysed using categorization and coding of the community. Categorization is the process of sorting units of data (such as term, phrases, references, bits of social action, etc.) with respect to properties or features of the documents.[38] Furthermore, this research use opens coding as the initial, unrestricted coding of data through the text of chat forum, speech or articles. The business value of social media.[39] includes "financial or business value"; "organizational effectiveness" such as "improved service time", "product or service quality", or "customer satisfaction" or "retention"; "personnel" such as "employee satisfaction"; "system" such as "information security", and "the financial". In addition, "the sociability values" and "usability values" also as second and third categorizing.[40] Determinants of sociability include obvious measures such as "participants" in a community, "the messages", "members' satisfaction", and "reciprocity", "on-topic messages", "trustworthiness" and several others. Category of "the usability" includes "errors", "productivity", "user satisfaction" and others.

Additional category also are "new way of thinking" about assessing the value of online communities such as "community membership", and "converting visiting members to using members"[41].

\section{RESULTS}

Analysis of several variables is presented in the following results and discussions: (1) Brand's business value; (2) Sociability performance of brand community; and (3) Usability of brand performance.

\section{A. Brand Business Values}

Based on the company's financial report, brand business values of each brand showed that in Indonesia, brand taking the top in 2017 is BCA, which grew its value $13 \%$ to US\$ 10.5 billion. Meanwhile, Telkomsel has raised two places to second place, growing $27 \%$ to US\$ 8.6 billion. This comes as the brand ventured into new digital services and power communications to reach consumers. The other brands got average high of brand values such as Matahari (US\$ $1.82 \mathrm{Bi}$ ), Pond's (US\$ 1.24 Bi), and Rinso (US\$ 1.14 Bi). Meanwhile, Ciputra (US\$ $512 \mathrm{Mi}$ ), Garuda Indonesia (US\$ $298 \mathrm{Mi}$ ), ACE (US\$ $287 \mathrm{Mi}$ ), and Indovision (US\$ $189 \mathrm{Mi).[42]} \mathrm{Toyota}$ Yaris brand value is not recorded in "Top 50 Most Valuable Indonesian Brands 2017" but its brand community in automotive category has a high cohesiveness. Moreover, Toyota All New Yaris the highest sales in its class of 1.109 units dropped its closest competitor in this segment, Honda Jazz. All New Yaris won 40.12\% of total hatchback segment sales in first quarter of 2018.[43] Thus, the ten brands value has a significant position in Indonesia based on the financial value. However, the significant contribution to intangible assets is also achieved through the existence of brand community both online and offline. Sociability values and usability values support the success of business values.

\section{B. Sociability Values}

Purpose. Sociability values reflect the nature of social interaction in an online community. Purpose of brand community is reflected in how many and what kinds of messages or comments (or comments per member) are being sent. Community can focus more on business value or vice versa, just social media for gathering only. Some purposes of sociability of brand communities show customer engagement.

First, focus on an interest. Interaction between brand community members is more concerned about sharing their experiences through social media (interactivity). As consumers, they tell about the brand. Brand is discussed and there is exchange of experience and information on product availability, spare-parts and after-sales service. However, some members talk about negative experiences and complain about brands and other community members provide explanations and solutions. Interest of brand community members in general reflects a process of disseminating information about the brand among the people.

Second, the brand community also reflects how on-topic is the discussion such as members' needs and information. Needs related to business value for the company appear and grow with the conversation that leads to the needs of consumers. Information submitted by producers on the promotion of sales raises the need for existing customers, especially the availability and price of spare parts, promotional programs bundling products, discounts and so forth. Third, two-way information (reciprocity) is needed, i.e. from corporations to members and vice versa. Information from producers is promotional or explanatory, while horizontal information among members is more of a sharing experience. Information and inter-member conversation developments are observed by the company as part of research or marketing intelligence to improve the quality of its products and services.

Fourth, service/support such as after-sales service is a much-discussed issue by brand community members. Conversation shows that the community wants the utility of the product to be optimal. They need the best service support from the company and its distributors. There are even members of the community proposing new ideas to improve the quality of after sales service. Not all members contribute well to the forum, but their involvement in the brand 
community serves as a moment of sharing and exchanging very useful information.

People. Measurement of "people" factor as the performance of brand community means how many and what kinds of people are participating in the community. Community members are active customers who have purchased products and may continue to be loyal to the brand. Brand communities in Indonesia generally are people who identify themselves as the urban and global citizen. Some of them play a role in enabling interactivity among members. Therefore, the experience of people using the product is the most discussed topic. People interact across age and gender for a product and specific to another particular product.

In other hand, the number of member of brand community shows the measurement in business value. The greater the number of brand community members the higher the potential business value. However, the large number of members is not necessarily effective to achieve high business value. The "people" factor also finds the average liveliness of interaction across all brand communities, brand acquisitions by individuals and intensive average groups. When the members are affiliated with each of their organizations, it is meaningful for the growths, and leadership in them is very influential.

People interact without space and time constraints as "active people". They exchange information and experiences and find solutions. Observations and interviews of researchers show that the brand community has been actively interacting since the early days of community formation. Usually some triggers turn on conversations in forums such as the emergence of variants or new products, spare parts, malfunctions, accidents and so on. Active people allow the brand community leads to positive consequences, such as greater community engagement. However, there are negative consequences, such as normative community pressure and (ultimately) reactance.[44]

Brand community can bring up people who act as coordinator or leader in the group. Perhaps the leader emerged from the administrator or an ordinary member with significant ideas and solutions during the interaction. The rest of the people role emerged as protagonists, comedians, prayers, etc. People in brand community practice have a physiology, interact with one another, function like apprenticeships, endow participants with cultural capital, produce a repertoire for insider sharing, generate opportunities, evince brand community vitality, and create value.[45]

Another aspect of "people" is individual and social group needs. The needs of individuals and groups are immediately identifiable from their conversations in the brand community. Individual specific needs can be generalized to create or improve product performance. Companies should be willing to share ideas with the community.

Organization needs are also formed within the brand community. Business-to-business (B2B) relationships are built on understanding the needs of the corporation today and in the future. The needs of the organization can be understood more deeply through the content of the conversation of the brand community members. Affiliates of brand community members network into companies. They are the officers and executives of various organizations in line with the line of business being occupied.
Policy. Each brand community has a policy that is applied to its members. The basic policy is about registration and code of behaviour for moderators. Moderation policies are used to deter uncivil behaviour as a filter of identity and character of members. Some verbal community brands do not write rules for their members against group policy. Probably because ethical issues are considered to be common knowledge, but some other community brands have written these terms verbally in rules such as flaming and uncivil behaviour as abusive language or harassment are not acceptable in most communities. Language guides do not exist except protocols guide in the form of recognition of community administrative authority.

Other policies on trustworthiness include (1) concerned with the security of credit card details, (2) medical or other personal information, (3) what they say. Trustworthiness is very important for brand community members in Indonesia because of the associated identity and ethics group.

In some brands, community reflects local characteristics with social-cultural attributes such as knowledge of the development of folklore, rituals, local history, and social norms. The peculiarities of these local attributes are often discussed.

Members generally adopt brand community policy because the moderator can issue an undisciplined member and / or insert new members. Thus, the policy runs effectively in the brand community in Indonesia.

\section{Usability Values}

Dialog and Social Support. Usability value reflects the nature of human-computer interaction. The brand community inter-members dialogue takes place within the duration of the varied time. Some hot topics are discussed for days and even appear again on other occasions, but there are trivial topics that get little response. Hot topics usually refer to the interests of consumers regarding product and after sales service, delivery, availability, quality, and so forth. Thus, conversation within the brand community can qualitatively improve productivity and social support. Moderators will maintain productivity through topic management.

Dialog that occurs generally in real time, for example an idea put forward directly responded by members of forums chat like WhatsApp and Line. In some social media like Facebook, Instagram and Blog usually delay and longer get responses. Generally, group conversations give members a sense of satisfaction and the dialogue becomes a consideration for retention. Human-Computer interaction can be hampered by errors but rarely occurs unless there is interference with the provider. Dialogue can shape social support through increasing members' cohesiveness. The achievable goal is the strengthening of online brand communities (OBCs) and consumer engagement. The results of this research support the findings of previous research that $\mathrm{OBC}$ dimensions consisting of brand orientation, internet-use, funding and governance. Meanwhile, three antecedents includes brand-related, social and functional are also proposed of consumer-OBC engagement.[46]

Information Design. The information design makes easy, convenient, and effective human-computer interaction. The design is prepared by the coordinator and is primarily sourced from the company. The design takes into account the creation 
of messages in text, visual, and audio-visual formats. Members of the brand community in Indonesia rarely use the "Help" menu on blogs. Members prefer to ask directly on real time social media forums. The desired information is needed to decide a retention action. So, for the most important member is information oriented goal. Thus, the community achieves a better level of satisfaction and the brand community really benefits them.

Community members generally do not understand in detail the system and information design but the ease of use and its benefits. Conversations in social media are remembered for consideration in purchasing decisions, involvement in loyalty programs and recommendations to other potential buyers. Error in the information system for users is considered a timeoff to rest from online activities.

Navigation. Navigate is part of the daily activity of brand community members. Wherever they are, smart phones are always in their hands. Average communities are always connected online. So, when asked, "How long does it take to learn to navigate through the communication software and web site or to find something?" The answers of community members are instantly getting what they are looking for with their handhelds. If the answer is not available in the chat forum, the member decides to search in Google and quickly obtains the required answers or information. With digital devices that always carry users, get where they want to go in a reasonable time.

When deciding to buy something, people always show the data information they get or transaction data they have done through the mobile phone screen to the cashier or to the customer service for execution. Navigation is very useful to complete the transaction (closing) so users always remember about navigation. This transaction process becomes the deciding factor of how satisfied are they, though sometimes errors occur but the kind of error is more to the low signal problem of the cellular operator.

Access. Accessibility of the brand community is done by installing a free software application available on Play Store. Users can choose any application easily unless specific software specific needs must be purchased formally via online or directly to the store. People install it freely whenever the software is needed. At the end is time to respond the forum in the group forum. Members of the full community brand in 24 hours and 7 days a week are available. It could even be said that people just are not available while sleeping even though their gadgets are online. Therefore, brand community members have no problem trying to download and run software.

\section{CONCLUSIONS}

Business value of brand is measured by the financial value. However, the significant contribution to intangible assets is also achieved through the existence of brand community both online and offline. Sociability values and usability values support the success of business values.

Measures of sociability include numbers of participants, amount of reciprocity, trustworthiness and others. Measures of usability include numbers of errors, productivity, user satisfaction and others. Brand communities development is a part of digital marketing communication strategy. It's have broader targets for building people engagement and business sustainability.

\section{ACKNOWLEDGMENT}

Considerable costs were incurred in the international conference and publishing of this paper. I am therefore grateful to the sources that provided funding to offset these costs. They include Binus University and The Ministry of Research, Technology and Higher Education of the Republic of Indonesia. It is a pleasure working these institutions.

\section{REFERENCES}

[1] World Bank (2018). Population, total. Httos://data.worldbank.org/ indicator/SP.POP.TOTL, retrieved on March 10, 2018.

[2] http://www.republika.co.id/berita/ekonomi/makro/18/01 /05/p23791415-bkpm-akan-perbanyak-investasi-sektorecommerce, retrieved on January 10, 2018. 10.00 AM.

[3] Chaffey, D., \& Ellis-Chadwick, F. (2012). Digital marketing (ed.). Edinburgh Gate, Harlow: Pearson Education.

[4] De Kare-Silver, M. (2014). Digital Insights 2020: How the Digital Technology Revolution is Changing Business and All Our Lives. Troubador Publishing Ltd.

[5] Ryan, D. (2016). Understanding digital marketing: marketing strategies for engaging the digital generation. Kogan Page Publishers.

[6] Heinze, A., Fletcher, G., Rashid, T., \& Cruz, A. (Eds.). (2016). Digital and Social Media Marketing: A Resultsdriven Approach. Taylor \& Francis.

[7] Lipschultz, J. H. (2014). Social media communication: Concepts, practices, data, law and ethics. Routledge.

[8] Kaplan, A. M., \& Haenlein, M. (2010). Users of the world, unite! The challenges and opportunities of Social Media. Business horizons, 53(1), 59-68.

[9] Bredl, K. (Ed.). (2017). Methods for analyzing social media. Routledge.

[10] Mahoney, L. M., \& Tang, T. (2017). Strategic social media: from marketing to social change. John Wiley \& Sons.

[11] Burgess, J., \& Green, J. (2013). YouTube: Online video and participatory culture. John Wiley \& Sons.

[12] Jenkins, H., Ito, M. \& Boyd, D. (2015). Participatory culture in a networked era: A conversation on youth, learning, commerce, and politics. John Wiley \& Sons.

[13] Tiwary, A. (2016). Online advertising: All information about online advertising at one place. Partridge Publishing.

[14] Martínez-López, F. J., Anaya, R., Aguilar, R., \& Molinillo, S. (2015). Online Brand Communities: Using the Social Web for Branding and Marketing. Springer.

[15] Buss, A., \& Strauss, N. (2009). Online Communities Handbook: Building your business and brand on the Web. New Riders.

[16] O'Shaughnessy, J., \& O'Shaughnessy, N. J. (2004). Persuasion in advertising. London: Routledge.

[17] Biocca, F. (2014). Television and Political Advertising: Volume I: Psychological Processes. Routledge.

[18] Armstrong, J. S. (2010). Persuasive advertising: Evidence-based principles. Palgrave Macmillan.

[19] Kim, A. J., \& Ko, E. (2012). Do social media marketing activities enhance customer equity? An empirical study of luxury fashion brand. Journal of Business Research, 65(10), 1480-1486.

[20] Tracy, K. (2009). "Community", in Littlejohn, S. W., \& Foss, K. A. (2009). Encyclopedia of communication theory (Vol. 1). Sage.

[21] Hollebeek, L. D., Glynn, M. S., \& Brodie, R. J. (2014). Consumer brand engagement in social media: 
Conceptualization, scale development and validation. Journal of interactive marketing, 28(2), 149-165.

[22] Brodie, R. J., Ilic, A., Juric, B., \& Hollebeek, L. (2013). Consumer engagement in a virtual brand community: An exploratory analysis. Journal of Business Research, 66(1), 105-114.

[23] Habibi, M. R., Laroche, M., \& Richard, M. O. (2014). The roles of brand community and community engagement in building brand trust on social media. Computers in Human Behavior, 37, 152-161.

[24] Laroche, M., Habibi, M. R., Richard, M. O., \& Sankaranarayanan, R. (2012). The effects of social media based brand communities on brand community markers, value creation practices, brand trust and brand loyalty. Computers in Human Behavior, 28(5), 1755-1767.

[25] Culnan, M. J., McHugh, P. J., \& Zubillaga, J. I. (2010). How large US companies can use Twitter and other social media to gain business value. MIS Quarterly Executive, 9(4).

[26] Hoffman, D. L., \& Fodor, M. (2010). Can you measure the ROI of your social media marketing?. MIT Sloan Management Review, 52(1), 41.

[27] Brettel, M., Reich, J. C., Gavilanes, J. M., \& Flatten, T. C. (2015). What drives advertising success on Facebook? an advertising-effectiveness model: Measuring the effects on sales of "likes" and other social-network stimuli. Journal of Advertising Research, 55(2), 162-175.

[28] Goh, K. Y., Heng, C. S., \& Lin, Z. (2013). Social media brand community and consumer behavior: Quantifying the relative impact of user-and marketer-generated content. Information Systems Research, 24(1), 88-107.

[29] Ding, Y., Phang, C. W., Lu, X., Tan, C. H., \& Sutanto, J. (2014, January). The role of marketer-and user-generated content in sustaining the growth of a social media brand community. In System Sciences (HICSS), 2014 47th Hawaii International Conference on (pp. 1785-1792). IEEE.

[30] Malhotra, A., Malhotra, C. K., \& See, A. (2012). How to get your messages retweeted. MIT Sloan Management Review, 53(2), 61.

[31] Smith, A. N., Fischer, E., \& Yongjian, C. (2012). How does brand-related user-generated content differ across YouTube, Facebook, and Twitter?. Journal of interactive marketing, 26(2), 102-113.

[32] Jahn, B., \& Kunz, W. (2012). How to transform consumers into fans of your brand. Journal of Service Management, 23(3), 344-361.
[33] Hennig-Thurau, T., Wiertz, C., \& Feldhaus, F. (2015). Does Twitter matter? The impact of microblogging word of mouth on consumers' adoption of new movies. Journal of the Academy of Marketing Science, 43(3), 375-394.

[34] Tirunillai, S., \& Tellis, G. J. (2012). Does chatter really matter? Dynamics of user-generated content and stock performance. Marketing Science, 31(2), 198-215.

[35] Khosrow-Pour, M. (Ed.). (2017). Handbook of Research on Technology Adoption, Social Policy, and Global Integration. IGI Global.

[36] Lin, H. F. (2007). The role of online and offline features in sustaining virtual communities: an empirical study. Internet Research, 17(2), 119-138.

[37] Creswell, J. W., \& Clark, V. L. P. (2017). Designing and conducting mixed methods research. Sage publications.

[38] Lindlof, T. R., \& Taylor, B. C. (2017). Qualitative communication research methods. Sage publications.

[39] Culnan, M. J., McHugh, P. J., \& Zubillaga, J. I. (2010). How large US companies can use Twitter and other social media to gain business value. MIS Quarterly Executive, 9(4).

[40] Preece, J. (2001). Sociability and usability in online communities: Determining and measuring success. Behaviour \& Information Technology, 20(5), 347-356.

[41] Cothrel, J. P. (2000). Measuring the success of an online community. Strategy \& Leadership, 28(2), 17-21.

[42] Milwardbrown, K. (2018). Brandz Top 50 Most Valuable Indonesian Brands 2017: Indonesian Brands coming of Age-Time to take on the world. WPP.

[43] Sudiarto, R. (2018),"Yaris Kuasai segmen Hatchback," SWA Magazine, March 19, 2018.

[44] Wirtz, J., Den Ambtman, A., Bloemer, J., Horváth, C., Ramaseshan, B., Van De Klundert, J., ... \& Kandampully, J. (2013). Managing brands and customer engagement in online brand communities. Journal of Service Management, 24(3), 223-244.

[45] Schau, H. J., Muñiz Jr, A. M., \& Arnould, E. J. (2009). How brand community practices create value. Journal of marketing, 73(5), 30-51.

[46] Algesheimer, R., Dholakia, U. M., \& Herrmann, A. (2005). The social influence of brand community: Evidence from European car clubs. Journal of marketing, 69(3), 19-34. 